\title{
EL COVID-19 Y SU IMPACTO EN EL ÁMBITO ECONÓMICO Y POLÍTICO
}

\author{
COVID-19 AND ITS IMPACT ON THE ECONOMIC \\ Alejandra Lizbhet Hernández Hernández ${ }^{1}$, Dra. María Pilar Acosta Márquez ${ }^{2}$, Dra. Flor Lucila Delfín Pozos ${ }^{3 y}$ \\ Dra. Eira López Fernández ${ }^{4}$
}

\section{RESUMEN}

Una pandemia como el COVID-19 no sólo ha puesto en riesgo la salud de las personas, sino que también a la economía global. La reacción de cada nación y las medidas a tomar ante esta pandemia son uno de los desafíos principales para afrontar esta crisis económica. En este trabajo se realiza una breve presentación y análisis sobre la situación mundial con respecto al COVID-19, haciendo hincapié en los aspectos político y económico de algunos países con el objetivo de realizar propuestas ante dicha situación.

PALABRAS CLAVE: Covid-19; pandemia; políticas en Covid-19; gobierno y Covid-19.

\begin{abstract}
A pandemic like COVID-19 has not only put people's health at risk but also the global economy. The reaction of each nation and the measures to be taken in the face of this pandemic are one of the main challenges to face this economic crisis. In this paper, a brief presentation and analysis is made of the world situation with respect to COVID-19, emphasizing the political and economic aspects of some countries with the aim of making proposals in the face of this situation.
\end{abstract}

KEYWORDS: Covid-19; pandemic; policies on Covid-19; government and Covid-19.

\footnotetext{
${ }^{1}$ Universidad Veracruzana, Facultad de derecho, México, alejdralcpvx@gmail.

${ }^{2}$ Universidad Veracruzana, Instituto de Investigaciones en Contaduría, México, pacosta@uv.mx

${ }^{3}$ Universidad Veracruzana, Instituto de Investigaciones en Contaduría, México, fdelfin@uv.mx

${ }^{4}$ Universidad Veracruzana, Instituto de Investigaciones en Contaduría, México, eilopez@uv.mx
} 


\section{INTRODUCCIÓN}

La situación actual que el mundo ha estado viviendo es alarmante, desde la perspectiva social haciendo referencia a las relaciones que los seres humanos llevan en su día a día, hasta las decisiones políticas que los representantes de las naciones han tomado para afrontar la pandemia y las afectaciones económicas que está generando.

Es impactante para las personas en el mundo ver cómo una enfermedad que en un principio se dio en oriente, generando así una epidemia en aquel lugar a finales de 2019, se ha convertido en una pandemia que ha generado problemas en la salud pública y en la economía. Millones de personas en riesgo de enfermedad y muerte, sistemas de salud colapsados, probable aumento de la muerte prematura resultado de la reducción en la actividad física durante el período de confinamiento, aunado a esto viene una recesión económica, con la pérdida de empleos, colapso total de ciertos sectores, como empresarial, turismo, aviación, entretenimiento y mercados financieros, todo ello con consecuencias para la salud y economía. A lo largo de la investigación se irán centrando las ideas a las estrategias políticas que han tomado algunas naciones para afrontar lo que está sucediendo, con ello viendo las afectaciones económicas.

En primera instancia se abordará el tema del COVID-19, dando así una definición concreta sobre qué es. Después un planteamiento concreto sobre la situación mundial de algunos países. Posteriormente se analizarán las estrategias que ha tomado cada nación desde la política y cuál es el efecto en la economía. Posteriormente se analizarán las situaciones para poder plantear propuestas de posibles soluciones.

\section{COVID-19}

Para la comprensión de la investigación es necesario definir ¿qué es el covid-19?, una vez aclarado se debe conocer, ¿cómo comenzó?

El COVID-19 es una enfermedad infecciosa causada por el virus SARS-CoV-2. Se detectó por primera vez en la ciudad china de Wuhan (provincia de Hubei), en diciembre de 2019. 
Habiendo llegado a más de 100 territorios, el 11 de marzo de 2020 la Organización Mundial de la Salud (OMS) la declaró pandemia.

Los principales síntomas asociados a este virus son fiebre (83-98\%), tos (76-82\%), disnea (31-55\%) y dificultad respiratoria (17-29\%), entre otros que aún están en estudio como hallazgos radiográficos en aquellos pacientes quienes presentaron un cuadro clínico grave, presentando alta similitud con la sintomatología causada por los coronavirus respiratorios del Síndrome Respiratorio Agudo Severo (SARS-CoV) y del Coronavirus del Síndrome Respiratorio del Medio Oriente (MERS-CoV). Entre dichos hallazgos se ha descrito en tomografías de pulmón opacidades en vidrio esmerilado, mixtas con imágenes de consolidación, agrandamiento vascular en la lesión y bronquiectasias de tracción (Rodríguez-Morales et al., 2020).

Para concluir esta parte los síntomas de COVID-19 son inespecíficos y su presentación, según la OMS, puede incluso carecer de síntomas (asintomático). Hasta el momento los síntomas más mencionados por los médicos para poder comenzar a tener sospechas sobre un posible diagnóstico son: fiebre, tos seca, fatiga, producción de esputo, disnea, dolor muscular o dolor en las articulaciones, dolor de garganta, dolor de cabeza, escalofríos, náuseas o vómitos, congestión nasal, diarrea, hemoptisis, congestión conjuntival, perdida del olfato y gusto, hipoxia silenciosa, entre otros.

\section{1 Situación}

De acuerdo con la información recabada en las noticias y artículos de los cuales se ha hecho análisis, aun se puede decir que las dudas sobre el origen de la enfermedad pueden seguir siendo un enigma. Sin embargo, de acuerdo a los documentos analizados ésta dio inicio en Wuhan (provincia de Hubei), tomado en un principio por parte de los representantes de gobierno como algo que fuese capaz de ser combatido, sin prever el caos global que éste desataría. 
Por un lado, este coronavirus se estaba presentando como una "gripe", a vista de algunas personas, sin embargo, cada caso particular que se presentaba, y al irlos sumando, se convirtieron en determinados grupos, diversificando los posibles síntomas ante el COVID19 e incluso extendiendo los grupos en casos asintomáticos. Al ser una enfermedad de rápido contagio, provoco que su propagación fuese rápida. Todo debido a los medios por los cuales se podía adquirir, siendo contacto cercano a las personas, como un saludo de mano, un abrazo e incluso hasta hablar de manera cercana, entre otras formas de adquirir esta enfermedad.

China tenía una postura en un principio insegura en cuanto a los riesgos que este virus causaría en su nación, en sus habitantes, aclarando que el impacto sobre el mundo aún no se divisaba. Conforme la enfermedad fue abarcando otros puntos dentro del país y no fue posible controlarla, comenzó a surgir pánico dentro de la población.

Otros países se mantenían en dos posibles posturas; unos escépticos de que pudiese llegar a su país, ya que la posición geográfica podría ser un impedimento, o lo veían como algo sin mayor trascendencia que decidieron ignorarlo. Aclarando que ambas posturas cometieron el mismo error, no prestar la debida atención a la situación. La primera postura, cayó en el error de no considerar a la globalización, ¿en qué aspecto?, en el hecho de que hay una gran concentración de turistas y más porque toda esta situación tuvo un gran impacto debido a la celebración del año nuevo chino. La segunda postura, el ignorar un virus, catalogado como epidemia en cierto país, fue un acto muy despreocupado por parte de otros países.

Cada país presento su postura, muchos representantes de estado buscaron o tuvieron un impacto diferente conforme a la reacción de su población. De modo que la reacción por parte de los representantes de nación y la reacción de los ciudadanos ha sido determinante en el impacto del COVID-19.

\section{2 Reacciones de algunos países frente al COVID-19}

\section{China}


La salud pública global mantuvo su atención en la infección causada por el nuevo coronavirus que la OMS denomino COVID-19. Esta epidemia, la cual ocurrió en dos grandes escenarios (el epicentro en China continental y específicamente la ciudad de Wuhan, provincia de Hubei), fue evolucionando de forma rápida, el 15 de febrero se habían notificado 66580 casos confirmados. En junio, la ciudad de Pekín hace frente a un nuevo brote de coronavirus calificado como "extremadamente grave". Para el 19 agosto reporta 84888 diagnosticados y 4634 muertes (JHU, 2020).

El resto del mundo inició con más de 526 casos, la mayoría fueron personas que habían viajado a China o que habían estado en contacto con alguna persona enferma. No obstante que se ha demostrado la transmisión de persona a persona, la propagación del virus en el resto del mundo fue limitada, en parte debido a que el número básico de reproducción (Ro) del virus es bajo (Ramos, 2020).

El gobierno de China, apoyado por la OMS, otros países más y algunas organizaciones no gubernamentales lograron contener parcialmente la epidemia, pues se habían reportado casos en por lo menos 34 provincias. Algunos países vecinos como Tailandia, Japón y comenzaron a registrar casos importados (Ramos, 2020).

\section{Italia}

De acuerdo con las fuentes consultadas, no se sabe a ciencia cierta en qué momento este virus comenzó su propagación, y fue catalogado como el lugar que todo mundo debía evitar. Con un inicio dificultoso, pero el 8 de marzo de 2020, el gobierno italiano implementó medidas extraordinarias para limitar la transmisión viral, incluida la restricción del movimiento en la región de Lombardía, que tenían la intención de minimizar la probabilidad de que las personas que no están infectadas entraran en contacto con personas infectadas. Italia continúa con un confinamiento estricto nacional y con medidas estrictas a los viajeros procedentes de varios países. Al 19 de agosto, Italia reporta 255000 infectados desde el inicio de la pandemia, y 35412 personas fallecidas (JHU, 2020). 
Todos los eventos deportivos, incluidos los partidos de fútbol, fueron suspendidos en todo el país. Las escuelas y universidades permanecerían cerradas hasta septiembre o conforme la enfermedad se fuera comportando.

\section{España}

Con más de 11000 casos y 491 muertes al 17 de marzo de 2020, reportando al 19 de agosto 370867 diagnosticados y 28797 fallecidos (JHU, 2020). Los puntos que tomaron con respecto a la situación fueron divididos en puntos:

1. El primero es la gobernanza. La coordinación es crucial en cualquier país, pero especialmente en uno como España en el que la responsabilidad de la salud recae en 17 regiones muy diversas. El Centro de Coordinación de Alertas y Emergencias Sanitarias (Health Alert and Emergency Coordination Center), creado en 2004, proporciona un mecanismo de coordinación entre los gobiernos nacionales y regionales. Sin embargo, este mecanismo no ha asegurado que las medidas estén completamente coordinadas. Por lo tanto, el País Vasco declaró una emergencia de salud pública antes que cualquier otra región, mientras que Cataluña solicitó un cierre completo de la región, incluido el cierre de los puertos aéreos, marítimos y terrestres. Madrid, La Rioja y Vitoria prohibieron las reuniones de más de 1000 personas. Estas medidas fueron acompañadas por una serie de medidas de distanciamiento social, incluido el cierre de escuelas.

2. El segundo bloque de construcción es el financiamiento. Antes del decreto, el gobierno central adoptó una serie de medidas financieras para apoyar el sistema de salud y proteger a las empresas. Había asignado 2800 millones de euros a todas las regiones para servicios de salud y creó un nuevo fondo con 1000 millones de euros para intervenciones de salud prioritarias. Sin embargo, estas cantidades deben verse en el contexto de casi una década de austeridad de la que el sistema de salud aún no se ha recuperado. 
3. Tercero, en la prestación de servicios, el Ministerio de Salud nacional ha desarrollado un conjunto de protocolos clínicos, publicados en su sitio web. Algunas regiones publican consejos adicionales y se actualizan, en algunos casos, diariamente. Las instalaciones de salud en las regiones más afectadas han luchado, con una capacidad inadecuada de cuidados intensivos y un número insuficiente de ventiladores en particular. Tanto Cataluña como Madrid cancelaron la cirugía que no es de emergencia y despejaron las camas cuando era posible. Las líneas de ayuda telefónica de COVID-19 tienen largas demoras o simplemente se colapsaron en algunas regiones. El nuevo decreto permite a las regiones hacerse cargo de la gestión de los servicios privados de salud, mientras que las instalaciones militares se utilizarán con fines de salud pública (Legido-Quigley, et. al., 2020).

4. El cuarto bloque es medicamentos y equipo. Hasta el momento, no se ha informado de una grave escasez, pero el suministro de equipos de protección personal en los centros de salud ha sido una preocupación en todas las regiones que conducen a la reutilización, a pesar de los riesgos conocidos. Hubo una escasez particular de mascarillas causadas por la compra temprana de pánico. Esta escasez ha fomentado la especulación, con laboratorios privados, por ejemplo, cobrando cantidades exorbitantes por las pruebas. En respuesta, el gobierno central centralizo las compras e introdujo controles de precios de los medicamentos. Exigir a las empresas que producen equipos relevantes que informen al gobierno central de sus existencias en 48 horas (Legido-Quigley, et. al., 2020).

5. El quinto bloque comprende trabajadores de la salud. Muchos informes sugieren que se estiran hasta el punto de agotamiento. Esta situación en parte refleja la escasez de personal existente, nuevamente después de años de austeridad con los bajos salarios resultantes. Antes del decreto, se sugirieron medidas irregulares e insuficientes, como cancelar las vacaciones o traer de vuelta al servicio de salud a las enfermeras y médicos retirados. Los problemas se ven exacerbados por la cuarentena de un número creciente de trabajadores de la salud expuestos a pacientes infectados. El nuevo decreto permite contratar graduados sin especialización, estudiantes de medicina y enfermería de último año y extender los contratos de los residentes de medicina. 
6. El bloque de construcción final, la información, se considera ampliamente proporcionado por las autoridades a todos los niveles de manera oportuna a través de las redes sociales y las redes sociales. Los medios de comunicación españoles han actuado en gran medida de manera responsable, difundiendo información precisa y desacreditando las noticias falsas que circulan en las redes sociales. Estos desarrollos han coincidido con cambios de actitudes entre la población española. Inicialmente, la enfermedad atrajo poca atención, pero esta calma pronto dio paso al pánico y al acaparamiento de suministros clave una vez que los casos comenzaron a aumentar. Sin embargo, se han observado muchas manifestaciones de solidaridad, como el apoyo a los profesionales de la salud, los más vulnerables y el distanciamiento social voluntario, incluido un mayor trabajo a domicilio.

\section{Estados Unidos de América}

La ciudad de Nueva York, el epicentro de la pandemia en EE.UU., hasta el 8 de abril el 28\% de las 4.009 muertes por COVID-19 eran personas afro, según datos revelados por el gobernador Andrew Cuomo. Al 19 de agosto se reportan en E.U. 5523826 confirmados y 173000 muertes desde el inicio de la pandemia (JHU, 2020).

El 29 de abril de 2020. Debido al temor de contraer esta enfermedad, un 79\% de la población estadounidense decidió adoptar medidas extras relacionadas con la higiene, como lavarse más a menudo, por ejemplo. El distanciamiento social también contó con una gran aceptación, siendo adoptada por el 78\% de la población participante en el estudio.

De acuerdo con una entrevista realizada por la BBC Mundo, sociólogos y personas especializadas, hablan sobre los principales sectores que se ven afectados en Estados Unidos de América, hablando de personas de origen afro, hispanos y personas indocumentados, ya que en los primeros casos se da el hecho de que son aquellos que siguen laborando, por la necesidad, los últimos al presentar síntomas no se presentan ante los hospitales por miedo a cómo serán tratados. Dentro de la entrevista se ve que todos los entrevistados coinciden en el hecho de que la cantidad y calidad de los datos que se presentan y con los que se cuenta para poder tomar decisiones más certeras frente a la situación, no siempre son certeros, generando coyunturas en las decisiones a tomar. 
Apuntando a la situación de los Estados Unidos de América, se divide en cuatro puntos sustanciales a la problemática (BBC-Mundo, 2020).

En primera instancia, se ve:

1. La reacción de la casa blanca frente a la situación.

La reacción que tuvo la casa blanca frente a la pandemia fue lenta, ya que los especialistas concuerdan en que se debieron tomar medidas urgentes como el aislamiento inmediato, que fue hasta mediados de marzo, y no solo la cancelación de los vuelos.

Estados Unidos, después de diez días de su primer caso el 21 de enero, decreto la prohibición de entrada a su país de extranjeros provenientes de China en los últimos 14 días.

En algunas declaraciones, Trump dijo que quería ser optimista y no alarmar a la población.

2. Los problemas con las pruebas para la diagnosticar la enfermedad

Hubo pruebas defectuosas y el acceso escaso a los exámenes para la población.

3. Sistema sanitario.

Por una parte, la falta de asistencia sanitaria en aumento, y por otra la existente cobertura mayormente basada en seguros privados ocasiona la detección tardía de la enfermedad. La consulta para las personas sin cobertura puede llegar a costar cientos de dólares.

4. Cada estado está por su lado.

Cada estado reacciono de diferente forma, unos imponiendo restricciones y otros no.

No obstante, de que cada país cuenta con agencias nacionales como los Centros para el Control y la Prevención de Enfermedades (CDC), cada uno tiene su propia infraestructura sanitaria pública y "parte del desafío se produce cuando no hay una estrategia nacional coordinada en el país y cada uno de los estados debe pensar en una estrategia de manera individual", apuntaba el experto de Harvard Thomas Tsai (BBC-Mundo, 2020). 


\section{México}

En México, el coronavirus inició el 28 de febrero, al dar positivo un residente tras volver de Italia. Horas después se confirmó el segundo caso en el estado de Sinaloa y otro más en la capital. "Estamos preparados para enfrentar esta situación", insistió el presidente en rueda de prensa. "No es algo terrible, fatal, ni siquiera es equivalente a la influenza (gripe)", subrayó entonces (Ginel, 2020).

El 19 de agosto México reporta 531239 diagnosticados desde el inicio de la pandemia, y han fallecido 577742 personas (JHU, 2020).

El presidente de la república mexicana tuvo una actitud condescendiente frente a la situación desde un principio, al saber del primer caso, esto a sabiendas de lo visto en diversos noticieros, no se exigió el aislamiento inmediato u obligatorio, no se previó en las instalaciones de salud sobre el posible problema que se avecinaría.

Aun con la falta de información por parte del gobierno, la población era consciente de lo que realmente comprendía dicho virus, dado que muchos sabían de ello, por lo que estaba ocurriendo en España, el impacto en Italia y los estragos que género en China. La población mexicana, de diversos estados, al saber de la existencia de posibles casos de COVID-19 entró en pánico y comenzaron a tomar medidas por ellos mismos. La reacción precipitada, genero un consumismo innecesario a lo que realmente debían hacer, dejando sin papel higiénico, canasta básica, bueno para resumir esta parte, las acciones de la población se asemejo lo que en otros países habían hecho.

No fue hasta el 20 de marzo de 2020 que el presidente decidió tomar una medida de prevención más trascendente, y fue el mandar a una cuarentena a todos los estudiantes de la república mexicana.

Un día después, acordó con EE. UU. restringir el tráfico en la frontera únicamente al comercio y a trabajadores con permiso migratorio. A partir del 23 de marzo, Ciudad de México, cierra cines, bares, restaurantes y otros establecimientos comerciales (Ginel, 2020) reabriéndose parcialmente el 11 de agosto con semáforo naranja. 
En el aspecto económico se comienzan a ver problemas para diversos sectores, por lo que, con la entrada en la Fase 2 de la pandemia el 24 de marzo, el Gobierno firmó un decreto presidencial que autoriza a los adultos mayores de 65 años, a las mujeres embarazadas y a los trabajadores con enfermedades crónicas a quedarse en sus hogares sin ser despedidos junto con el goce de sueldo (Ginel, 2020).

El 23 de marzo de 2020, el presidente informa la no condonación de impuestos a las grandes corporaciones por el impacto de la contingencia y que solo se proporcionarán créditos a las empresas pequeñas.

En México al 19 de agosto se reportan 531239 confirmados y 57774 defunciones (JHU, 2020).

\section{3 Estrategias que ha tomado cada nación desde el punto de vista político}

Las posturas mencionadas anteriormente frente al COVID-19 fueron dejadas de lado y cada país comenzó a entrar en pánico, debido a que muchos veían que, si una potencia como lo era china no era capaz de contenerlo, cómo países tercer mundistas lo contendrían. En un principio de la situación, primeros meses del año 2020. Pese a los miedos de cada nación a principios de abril China presenta su primer día sin muertes, haciendo que la esperanza se cimentara en cada nación, con respecto a la contención del virus.

Frente a la situación que se estaba presentando y se está viviendo hoy en día, las medidas tomadas en los países alrededor del mundo acordes a cada situación fueron similares, más el efecto en cuanto a las personas afectadas fue la diferencia. Las medidas adoptadas por la mayoría se enlistarían de la siguiente manera:

- Medidas de sanitarias.

1. Aislamiento social.

2. Lavado continúo de manos.

3. Uso de cubre-boca, gel antibacterial.

- Medidas educativas.

1. Cierre de escuelas de forma indefinida. 


\section{Alumnos en cuarentena obligatoria}

3. Actividades virtuales y a distancia.

- Medidas laborales.

1. Las personas donde su labor no fuese indispensable fueron enviados a cuarentena, para evitar la propagación de la enfermedad.

2. Aquellos que viviesen al día, debían o deben llevar cubrebocas de forma obligatoria.

3. Quienes fuesen del sector vulnerable (mujeres embarazadas, personas mayores, personas con diabetes o alguna enfermedad grave o de riesgo, frente al virus.) en su mayoría debían y deben ser enviados a casa, sin ser despedidos, ya que, es época de crisis.

- Otras medidas dirigidas al sector económico.

I. Se cancelaron eventos que tuviesen altas concentraciones de personas (ferias, fiestas, eventos masivos musicales, conciertos, partidos de algún deporte, entre otros.)

II. Los aeropuertos fueron restringidos a turistas y solo se permitan en casos de empresarios o personas con necesidad de urgencia (a criterio de cada país).

III. En algunos países, algunos bancos decidieron dejar correr algunas cuentas sin el aumento de los intereses a las mismas.

IV. El movimiento de turistas en cada región del mundo fue suspendido.

V. Negocios que no fuesen de primera necesidad debían o deben mantenerse cerrados.

VI. En algunos países, se tomaron medidas con respecto a algunos productos tanto de canasta básica como de higiene, en lo que respecta a sus precios y venta de productos por familia.

VII. La bolsa de valores en cada país tuvo y tiene un papel dentro de la situación, en cómo se está llevando a cabo dicha situación.

Esas fueron algunas de las medidas en ciertos aspectos específicos, que están permeando en cada nación, alrededor del mundo. 


\section{4 El efecto en la economía}

La incertidumbre que ha generado el COVID-19 ha golpeado los mercados de valores alrededor del mundo. Ahondando en temas que afecten a los diversos mercados, se hablará de mercado de valores, el sector bancario - regulación prudencial, las organizaciones multilaterales y organismos internacionales, las políticas macroeconómicas - bancos centrales y la relación con el gobierno Corporativo.

Wall Street aceleró su desplome y cerró con el Dow Jones desplomándose en un 10\%, su peor caída porcentual desde el "Lunes Negro" de 1987. Esta caída ocurre después de que el presidente de Estados Unidos, Donald Trump, ordena suspender vuelos desde Europa a Estados Unidos para contener el virus y a la drástica inyección de liquidez de $\$ 1,5$ billones en el sistema financiero anunciada por la Reserva Federal. Los informes del Banco Central Europeo no son nada alentadores para calmar la volatilidad del mercado. Hay caídas fuertes para las empresas energéticas y las financieras (ABC, 2020).

Las bolsas y reguladores del mercado de valores de diferentes jurisdicciones decidieron implementar estrategias para tratar de aminorar los efectos económicos debido a la pandemia.

En lo que respecta a la bolsa de valores en los diversos mercados, los puntos a considerar eran las posibles o la suspensión de la negociación de acciones, otros puntos recaían en la prohibición de ventas en corto.

Para mayor análisis se verán las bolsas de valores de cuatro países:

NYSE (New York Stock Exchange): Las grandes ventas registradas el jueves 12 de marzo de 2020 en la Bolsa de Valores de Nueva York llevó a una caída momentánea de más de 2,000 puntos o alrededor de $9 \%$ aumentando las pérdidas de los últimos días. Al caer el indicador S\&P a 7\% se detonó una suspensión de las cotizaciones por 15 minutos y al reanudarse las operaciones las acciones cayeron mucho más. Registrándose como la segunda paralización de este tipo en esa semana. A las 9:35 a.m. del 12 de marzo de 2020 (cinco minutos después de abrir) se decretó la pausa de 15 minutos (Remolina, 2020) (McCabe and Ostroff, 2020). 
Aquí se hace hincapié en que la NYSE es considerada una de las bolsas más importantes a nivel mundial y la cual mueve grandes cantidades de dinero al año.

México: La Bolsa mexicana suspendió el 12 de marzo la negociación tras caer un 7\%. Algunas de las compañías que más pierden son: Genomma Laboratorios (-14.47\%), Grupo Aeroportuario del Pacífico (-13.69\%), Grupo Financiero Banorte (-12.93\%), Grupo Televisa $(-11.98 \%)$ y Alfa $(-10.58 \%)$ (El Economista, 2020).

Medio Oriente: También, las bolsas se hundieron, con pérdidas del 9.4\% en Arabia Saudita, del $10.3 \%$ en Kuwait y del $9 \%$ en Kuwait. En estos países del Golfo, el 9 de marzo, cuando una acción o toda la bolsa caen un $10 \%$ o aumentan un $15 \%$, los intercambios en bolsa quedan automáticamente suspendidos. El 2 y 3 de marzo, las acciones de la empresa más grande cotizada del mundo, pierde 320000 millones de dólares (Infobae, 2020) (Fahy, 2020).

Tal vez el tema de la bolsa no sea del todo conocido, sin embargo, la mayoría tiene la noción sobre los posibles efectos que se pueden presentar si hay perdidas.

Pasando al hecho de la prohibición de ventas en corto.

Europa: Los hedge funds apostaron miles de millones contra empresas clave de toda Europa, como Allianz, Bayer, Unilever, Total, Nokia, Enel, Telefónica, Santander y BBVA, provocando un derrumbe de sus cotizaciones poniendo en peligro la continuidad de sus operaciones (Marco, 2020).

En el sector bancario-regulación prudencial.

Reino Unido: Los bancos podían seguir ofreciendo préstamos a empresa y hogares a pesar de estar con los efectos de recesiones económicas sustanciales y prolongadas tanto en el Reino Unido como en las economías globales y de las caídas en los precios de los activos mucho más grandes que los experimentados recientemente a causa del virus (Remolina, 2020) (Bank of England, 2020). 
Viendo las organizaciones multilaterales y organismos internacionales en el caso de Brasil.

Brasil: El Comité de Basilea no se pronunció al respecto, pero el BIS en su reporte trimestral dedicó un capítulo a analizar qué decían los mercados de valores cuando reaccionan a epidemias como el SARS de 2003 o epidemias como el COVID-19. No obstante, no se hizo ninguna recomendación en materia de regulación prudencial sobre el tema (Zakrajšek, 2020).

Pasando a las políticas macroeconómicas - Bancos Centrales, adoptadas en cada país o sector del mundo:

Europa: El BCE (Banco Central Europeo) llevo a cabo, temporalmente, operaciones adicionales de refinanciación a largo plazo (LTRO por sus siglas en inglés) con el fin de proporcionar apoyo de liquidez inmediato al sistema financiero de la zona del euro. Las LTRO proporcionarían liquidez en condiciones favorables para cerrar el período hasta junio de 2020 (Lagarde, 2020).

Estados Unidos: La NY Fed inyectó 1.5 trillones de dólares para hacer frente a la situación a través de préstamos a corto plazo para garantizar la liquidez del sistema. Además, desde el organismo anunció que se estaban estudiando cambios en su programa de compras de deuda con el fin de abordar las interrupciones altamente inusuales en los mercados de financiación del Tesoro asociados con el brote de coronavirus. La Fed de Nueva York puso a disposición del mercado todas las semanas -hasta el 13 de abril- hasta 500000 millones a un mes y otros tantos a tres meses de vencimiento. Asimismo, aseguro que seguirá ofreciendo al menos 175 000 millones de dólares en operaciones repo diario y al menos 45000 millones en operaciones repo a dos semanas dos veces por semana (Morales, 2020) (New York Fed, 2020). 
Colombia: El Banco de la República estableció un nuevo mecanismo de cobertura cambiaria, para facilitar la negociación de moneda extranjera con tipo de cambio flexible, mediante operaciones 'forward' de cumplimiento financiero. De acuerdo con el Emisor, las condiciones del nuevo mecanismo comprenden subasta de precio uniforme, monto por 1000 millones de dólares, el precio forward se determinará en la subasta y el plazo será de 30 días que podrán ser renovables. Este proceso facilitaría la negociación en moneda extranjera de los participantes del mercado en el contexto del esquema de inflación objetivo con tipo de cambio flexible (Banrep, 2020).

Para concluir este apartado se hablará sobre todo lo ya mencionado y su relación con el gobierno corporativo.

Inglaterra y Gales: En el documento "Coronavirus (COVID-19): Considerations for Group Auditors", publicado por El Instituto de Contadores y Auditores (Institute of Chartered Accountants in England and Wales), se muestra información acerca de cómo identificar las auditorías impactadas, categorizar las auditorías, discutir la modificación de los plazos de presentación de informes, considerar actividades alternativas para demostrar el examen y la evaluación del equipo componente donde originalmente se planeó una visita del auditor del grupo, considerar implicaciones más amplias en el informe de auditoría. Estas últimas implicaciones se refieren a evaluar si la base de la empresa es apropiada, determinar si existen efectos contables más amplios y examinar los informes de los administradores presentados a la Junta acerca del impacto del coronavirus, por ejemplo, acerca de los principales riesgos para su negocio (ICAEW, 2020).

Aclarando y recalcando que cada país se ve relacionado de forma estrecha en lo referente a la economía global, y las decisiones entre estos se ven afectadas, implicando pérdidas globales y desbalances en cada país. 


\section{CONCLUSIONES Y ALTERNATIVAS PERTINENTES}

En primera instancia hay que aclarar que la solución no está en paralizar en su totalidad la bolsa de valores, más sí en tomar las medidas necesarias para protegerlas de posibles problemas que se presenten en lo que resta de la situación (contingencia en cada país).

El segundo punto a considerar sería la importancia entre las medidas de coordinación con respecto a las políticas de salud y la disposición laboral de la población, es decir, que si se va a aplicar una medida para la contención del virus, el gobierno de cada país debe prever las posibles consecuencias, para aquellas personas que van al día (desde prestamos, créditos hipotecarios, medidas bancarias, etc.), en la media para que ciertos sectores no se vean tan afectados y puedan seguir, pese a las circunstancias. Aclarando que todo debe ser abalado por los gobiernos de forma legal y sin posibles repercusiones negativas.

Para concluir en lo que respecta a la organización y medidas que toman los bancos para mitigar los daños a la economía, debe existir concordancia entre los recortes realizados, ya que en esta línea podemos ver que al tener clara la información y los datos que se vayan arrogando, pueden llegar a la creación de un modelo concreto, auxiliando a la economía con mayor eficacia.

Muchos de los datos mencionados a lo largo de este apartado fueron citados, ya sea por las fechas o porcentajes arrojados y con el fin de que aquellos interesados en algún tema en específico puedan ir e indagar más al respecto.

\section{REFERENCIAS}

ABC (2020). El Dow Jones se desploma un $10 \%$ pese a la inyección de liquidez de 1,5 billones de dólares de la Fed. 15 de 03 de 2020. ABC Economía. Recuperado el 15 marzo 2020 de https://www.abc.es/economia/abci-jones-desploma-10--por-ciento-pese-inyeccion-liquidez15-billones-dolares-202003122251_noticia.html

Bank of England. (2020). Bank of England measures to respond to the economic shock from COVID19. (11 de 03 de 2020). BANK OF ENGLAND. Recuperado el 15 de 05 de 2020, de BANK OF ENGLAND. https://www.bankofengland.co.uk/news/2020/march/boe-measures-torespond-to-the-economic-shock-from-covid-19

Banrep- Banco de la República-Colombia. (2020). En sesión extraordinaria, la Junta Directiva adoptó un conjunto de medidas encaminadas a reforzar la liquidez del sistema de pagos, en el contexto de la extrema volatilidad global (12 de 03 de 2020). Medidas del Banco de la República para enfrentar el impacto del Covid-19 en la economía. Banco de la republica- 
Colombia. Recuperado el 15 de 05 de 2020, de Banco de la republica-Colombia.: https://www.banrep.gov.co/es/comunicado-junta-directiva

BBC-Mundo, (2020). Coronavirus en Estados Unidos: 4 claves que explican el enorme impacto del coronavirus en el país con más muertos por covid-19 del mundo (13 de 04 de 2020). BBC News Mundo. Recuperado el 15 de 05 de 2020, de BBC News Mundo.: https://www.bbc.com/mundo/noticias-internacional-52273159

El Economista. (2020). Bolsa Mexicana de Valores suspende operaciones tras caída de $7.0 \%$ en la apertura. EL ECONOMISTA. (12 de 03 de 2020). Recuperado el 15 de 05 de 2020, de EL ECONOMISTA.: $\quad$ https://www.eleconomista.com.mx/mercados/Bolsa-Mexicana-deValores-suspende-operaciones-tras-caida-de-7.0-en-la-apertura-20200312-0062.html

Fahy, M. (2020). More than $\$ 200$ bn wiped off Gulf markets in huge one-day slump. The National. CORONAVIRUS (09 de 03 de 2020). Recuperado el 15 de 05 de 2020 , https://www.thenational.ae/business/markets/more-than-200bn-wiped-off-gulf-markets-inhuge-one-day-slump-1.989732

Ginel, F. H. (2020). Covid-19 (28 de 03 de 2020). Newtral. Recuperado el 15 de 05 de 2020, https://www.newtral.es/mexico-medidas-coronavirus/20200328/

ICAEW (2020). Coronavirus (covid-19): Considerations for group auditors. 18 de 03 de 2020. ICAEW-The Institute of Chartered Accountants in England and Wales. Recuperado el 19 de agosto 2020 en https://www.icaew.com/-/media/corporate/files/technical/audit-andassurance/audit-and-assurance-faculty/considerations-for-group-auditors-impacted-bycoronavirus-guide.ashx

Infobae. (2020). Las bolsas del Golfo se derrumban tras la caída del petróleo, 9 de 03 de 3030, Infobae. Recuperado el 20 marzo 2020 de https://www.infobae.com/america/agencias/2020/03/09/las-bolsas-del-golfo-se-derrumbantras-la-caida-del-petroleo/

JHU- Johns Hopkins University, (2020). COVID-19 Dashboard by the Center for Systems Science and Engineering (CSSE) at Johns Hopkins University (JHU). Recuperado el 19 de 08 de 2020 , https://gisanddata.maps.arcgis.com/apps/opsdashboard/index.html\#/bda7594740fd4029942 $3467 \mathrm{~b} 48 \mathrm{e} 9 \mathrm{ecf6}$

Lagarde, C. (2020). ECB press conference - introductory statement (12 de 03 de 2020). BIS. Recuperado el 15 de 05 de 2020, https://www.bis.org/review/r200312b.htm

Legido-Quigley, H., Mateos-García,J. T. Regulez Campos,V., Gea-Sánchez, M., Muntaner, C. y McKee, M. (2020). The resilience of the Spanish health system against the COVID-19 pandemic. THE LANCET HEALTH, Vol 5 May 2020. Recuperado el 15 de 05 de 2020, https://www.thelancet.com/journals/lanpub/article/PIIS2468-2667(20)30060-8/fulltext

Marco, A. (2020). Las empresas piden a la CNMV prohibir los ataques de los bajistas ante el crash del IbexNewsLetter. el confidencial. (12 de 03 de 2020) Recuperado el 15 de 05 de 2020, de NewsLetter: el confidencial.: https://www.elconfidencial.com/empresas/2020-03-12/lasempresas-piden-a-la-cnmv-prohibir-los-ataques-de-los-bajistas-ante-el-crash-delibex_2494171/

McCabe, C. and Ostroff C.(2020). Stocks Plunge 10\% in Dow's Worst Day Since 1987. The Wall Street Journal (12 de 03 de 2020). Recuperado el 14 de 05 de 2020, de The Wall Street Journal.: $\quad$ https://www.wsj.com/articles/global-stocks-follow-u-s-markets-lower$11583975524 ? \bmod =\mathrm{e} 2 \mathrm{tw}$ 
Morales, Y. (2020). Fed anuncia que inyectará hasta 1.5 billones de dólares. EL ECONOMISTA. (13 de 03 de 2020). Recuperado el 15 de 05 de 2020, de EL ECONOMISTA.: https://www.eleconomista.com.mx/economia/Fed-anuncia-que-inyectara-hasta-1.5billones-de-dolares-20200313-0010.html

New York Fed. (2020). Statement Regarding Treasury Reserve Management Purchases and Repurchase Operations. (12 de 03 de 2020). New York Fed. Federal Reserve Bank of New York. Recuperado el 15 de 05 de 2020, de https://www.newyorkfed.org/markets/opolicy/operating_policy_200312a

Ramos, C. (2020). Covid-19:la nueva enfermedad causada por un coronavirus. Salud pública de Mexico. 62(2), 225 - 227. Ciudad de México.

Remolina, N. (2020). Respuestas de Supervisores y Reguladores Financieros al COVID-19 (Financial Regulators' Responses to COVID/19) (March 13, 2020). Disponible en SSRN: https://ssrn.com/abstract=3554557 or http://dx.doi.org/10.2139/ssrn.3554557

Rodríguez-Morales, Alfonso J, Sánchez-Duque, Jorge A, Hernández Botero, Sebastian, Pérez-Díaz, Carlos E, Villamil-Gómez, Wilmer E, Méndez, Claudio A, Verbanaz, Sergio, Cimerman, Sergio, Rodriguez-Enciso, Hernan D, Escalera-Antezana, Juan Pablo, Balbin-Ramon, Graciela J, Arteaga-Livias, Kovy, Cvetkovic-Vega, Aleksandar, Orduna, Tomas, SavioLarrea, Eduardo, \& Paniz-Mondolfi, Alberto. (2020). Preparación y control de la enfermedad por coronavirus 2019 (COVID-19) en América Latina. Acta Médica Peruana, 37(1), 3-7. https://dx.doi.org/10.35663/amp.2020.371.909

Zakrajšek, E. y Ávalos F. (2020). Covid-19 and SARS: what do stock markets tell us? , 01 de 03 de 2020). BIS. Recuperado el 15 de 05 de 2020, de BIS.: https://www.bis.org/publ/qtrpdf/r_qt2003w.htm 